\title{
Original Article \\ Gingyo-San Enhances Immunity and Potentiates Infectious Bursal Disease Vaccination
}

Che-Ming Hung, ${ }^{1,2}$ Chia-Chou Yeh, ${ }^{3}$ Kowit-Yu Chong, ${ }^{4}$ Hsiao-Ling Chen, ${ }^{5}$ Jiun-Yu Chen, ${ }^{2}$
Shung-Te Kao, ${ }^{2}$ Chih-Ching Yen, ${ }^{2,6}$ Ming-Hsien Yeh, ${ }^{3}$ Maw-Sun Lin, ${ }^{2}$ and Chuan-Mu Chen ${ }^{2,6}$

${ }^{1}$ Animal Industry Division, Livestock Research Institute, Council of Agriculture, Tainan 712, Taiwan

${ }^{2}$ Department of Life Sciences, National Chung Hsing University, Taichung 402, Taiwan

${ }^{3}$ Department of Chinese Medicine, Buddhist Dalin Tzu Chi General Hospital, Chia-Yi 622, Taiwan

${ }^{4}$ Department of Medical Biotechnology and Laboratory Science, Chang Gung University, Tao-Yuan 333, Taiwan

${ }^{5}$ Department of Molecular Biotechnology, Da-Yeh University, Changhwa 515, Taiwan

${ }^{6}$ China Medical University Hospital, Taichung 404, Taiwan

Correspondence should be addressed to Chuan-Mu Chen, chchen1@dragon.nchu.edu.tw

Received 16 July 2008; Accepted 28 January 2009

Copyright (C) 2011 Che-Ming Hung et al. This is an open access article distributed under the Creative Commons Attribution License, which permits unrestricted use, distribution, and reproduction in any medium, provided the original work is properly cited.

\begin{abstract}
The purpose of the present study was to investigate the effects of Gingyo-san (GGS), a traditional Chinese medical formula, on peripheral lymphocyte proliferation and serum antibody titers in chickens vaccinated against the infectious bursal disease (IBD) virus. Treatment groups were fed one of three doses of GGS in their diet $(0.5 \%, 1.0 \%$ and $2.0 \%, \mathrm{w} / \mathrm{w})$, and the IBD vaccine was administered at 1 and 3 weeks of age. At Weeks 8,12 and 16, changes in serum IBD antibody titers were measured via the micro-method and $\mathrm{T}$ cell proliferation. In gene expression experiments, GGS-treated peripheral T lymphocytes were stimulated with concanavalin A (ConA) for $24 \mathrm{~h}$. The mRNA expression of interleukin-2 (IL-2), interferon- $\gamma$ (IFN- $\gamma$ ), interleukin-4 (IL-4) and interleukin-12 (IL-12) was determined using a semi-quantitative RT-PCR assay. The results showed that a low dose of GGS could significantly raise the antibody titers. Medium and high doses of GGS enhanced IL-2 and IFN- $\gamma$ production. GGS altered the expression of IL-4 and IL-12 in T lymphocytes. CD4 $4^{+}$T lymphocyte development was also skewed towards the Th1 phenotype. GGS enhanced cell-mediated immunity and augmented the effects of IBD vaccination in strengthening subsequent anti-viral responses.
\end{abstract}

\section{Introduction}

Many traditional Chinese medicines (TCM) and their ingredients have been reported to enhance immunity [1-3], and they have great potential in many practical applications. Immunomodulation is an important process for infectious diseases, especially viral diseases. These diseases result in huge losses in the domestic animal and poultry industries [4]. Some infectious diseases remain hard to control due to the heterogeneity of microorganisms, the inferior quality or improper storage and transport of vaccines, and the occurrence of immunosuppressive diseases. The use of an immunopotentiator with a vaccine could improve the efficacy and decrease the toxicity of vaccination [5].

Infectious bursal disease (IBD) has a sudden onset with a short incubation period (2-3 days). Morbidity is usually
$100 \%$, but mortality varies depending on the virus strain $[4,6,7]$. The IBD virus is ubiquitous, is resistant to a variety of disinfectants, and is environmentally stable. Chickens are widely exposed to the IBD virus worldwide, which leads to multi-billion dollar losses in the poultry industry [8]. Serological evidence of natural infection with the virus showed infection levels of $58.6 \%$ in Taiwan [9]. Strategies to control IBD are largely based on vaccination programmes.

In TCM, Gingyo-san (GGS), is a crude drug containing extracts from 10 medicinal plants. In TCM therapy, GGS is frequently used to treat pulmonary disorders including the common cold and bronchial infections [2]. Experiments conducted in Japan have revealed that GGS has antipyretic and antiviral effects $[10,11]$. Pharmacological studies of GGS indicate that it is effective at alleviating fever, relieving pain, counteracting hypersusceptibility and counteracting 
bacterial and viral infections [12]. In animal trials, GGS also exhibited significant therapeutic effects on bacterial and viral infections in mice [13]. In addition, two components identified from GGS were shown to exhibit antiviral activities in mice infected with the influenza virus [11,14]. Recently, it has been reported that GGS exerts an immunomodulatory effect during acute respiratory distress syndrome (ARDS), through the down-regulation of inflammatory cytokines and the up-regulation of anti-inflammatory cytokines [2]. The use of GGS in feed additives as part of a preventative programme has been implemented on domestic farms in China.

In this study, we investigated the possibility of using GGS as an immune stimulator to enhance peripheral lymphocyte proliferation and serum antibody titers in chickens vaccinated against the IBD virus. The dose-dependent responses of immune enhancement to GGS were also evaluated.

\section{Methods}

2.1. Preparation of GGS Extract. Medicinal plants were provided by Koda Pharmaceutics Ltd (Taoyuan, Taiwan) for the preparation of the GGS extract. GGS is commercially available in Taiwan and Japan. The preparation is a mixture of 10 crude plant ingredients: Lonicera japonica Thunb. (herb. no. 10802; Caprifoliaceae), Forsythia suspensa Thunb. (herb. no. 11005; Oleaceae), Mentha haplocalyx Briq. (herb. no. 11604; Lamiaceae), Schizonepeta tenuifolia Briq. (herb. no. 11002; Lamiaceae), Glycine max Merr. (herb. no. 11105; Fabaceae), Glycyrrhiza uralensis Fisch. (herb. no. 10503; Fabaceae), Platycodon grandiflorum Jacq. (herb. no. 11004; Campanulaceae), Lophatherum gracile Brongn. (herb. no. 11106; Poaceae), Arctium lappa L. (herb. no. 10404; Asteraceae) and Phragmites communis Trin. (herb. no. 12001; Poaceae), at a ratio of $10: 10: 4: 4: 5: 5: 6: 5: 6: 10$. The voucher specimen and method of extraction and analysis of GGS were as described previously [2]. The extract was dissolved in pyrogen-free isotonic saline (YF Chemical, Taipei, Taiwan) and filtered through a $0.2 \mathrm{~mm}$ filter (Microgen, Laguna Hills, CA, USA) before use. The high-performance liquid chromatography (HPLC) chromatogram of the GGS for quality control is shown in Figure 1.

2.2. Reagents. RPMI-1640 medium (Roswell Park Memorial Institute-1640 medium; GIBCO Invitrogen, Carlsbad, $\mathrm{CA})$, supplemented with benzylpenicillin $\left(100 \mathrm{IU} \mathrm{mL}^{-1}\right)$ and streptomycin $\left(100 \mathrm{IU} \mathrm{mL}^{-1}\right)$, was used for in vitro cell culture, washing and re-suspending cells, and diluting the mitogen [15]. Concanavalin A (ConA) (Sigma Chemicals, St Louis, MO) was dissolved in the RPMI-1640 medium to a final concentration of $0.025 \mathrm{mg} \mathrm{mL}^{-1}$. 3-(4, 5-Dimethylthiazol-2-yl)-2,5-diphenyl-tetrazolium bromide (MTT, Amersco Inc., Solon, OH) was dissolved in calciumand magnesium-free (CMF) phosphate-buffered saline (PBS, $\mathrm{pH}$ 7.4) to achieve a concentration of $5 \mathrm{mg} \mathrm{mL}^{-1}$. These reagents were filtered through a $0.22 \mu \mathrm{m}$ filter $[16,17]$. The ConA solution was stored at $-20^{\circ} \mathrm{C}$ and the MTT solution and RPMI-640 media were stored at $4^{\circ} \mathrm{C}$. The lymphocyte separation medium (Ficoll-Hypaque) and dimethyl sulphoxide (DMSO) were purchased from Sigma Chemicals.

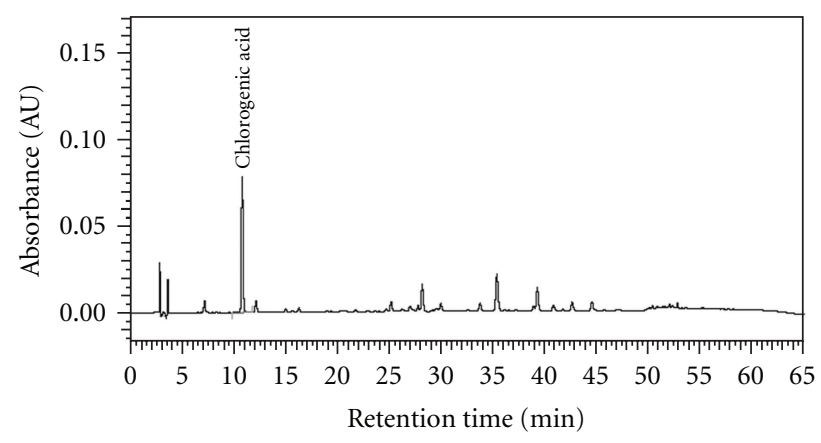

FIGURE 1: HPLC chromatogram of GGS. The solution of GGS was prepared by dissolving it in pyrogen-free isotonic saline $(10 \mathrm{mg} / 100 \mathrm{~mL})$. The major active compound of chlorogenic acid $\left(0.081 \mathrm{mg} \mathrm{mL}^{-1}\right)$ was detected at $10.77 \mathrm{~min}$ retention time. The injection volume was $10 \mu \mathrm{L}$, and the flow rate was $1.0 \mathrm{~mL} \mathrm{~min}^{-1}$.

2.3. Animals. One-day-old Taiwanese broilers were purchased from the Livestock Research Institute and reared in concrete floor pens $(1.8 \mathrm{~m} \times 1.8 \mathrm{~m}$ per pen $)$ padded with rice hull litter in an open-sided growing house until 16 weeks of age. The chickens were fed the basal corn-soybean meal diets based on the guidelines suggested by National Research Centre (NRC) [18] and the Extension Booklet for the Taiwan country broiler [19]; these guidelines were formulated to meet the nutritional requirements for Taiwan country broilers at different stages of the life cycle. Feed and water were supplied ad libitum. All experimental procedures were approved by the Institutional Animal Care and Use Committee of the Livestock Research Institute.

2.4. Experimental Design. Forty chickens were randomly divided into four groups containing equal numbers of birds of similar body weights (the average BW was $32 \mathrm{~g}$ ). Group 1 was the medicine-free control. Groups 2-4 were fed GGS powder at one of three concentrations: $0.5 \%(\mathrm{w} / \mathrm{w}$, low dosage), $1 \%$ (medium dosage) and 2\% (high dosage), respectively. The IBD vaccine was administered twice at 14-day intervals. The first vaccine (Bursine-2, Fort Dodge Animal Health Inc., Charles, IA) was orally administered at 1 week of age and the second (IBD BLEN, Merial Select Inc., Gainesville, GA) at 3 weeks of age. At Weeks 8,12 and 16, six chickens were sampled randomly from each group for the examination of peripheral lymphocyte proliferation by the MTT assay. At Weeks 8 and 16, eight additional chickens were sampled randomly from each group for the determination of serum IBD antibody titers using an enzyme-linked immunosorbent assay (ELISA) kit [20]. The animal trials were repeated twice.

2.5. Blood Sample Collection and Analysis of Biological Parameters. Blood samples were collected from the wing vein with a $24 \mathrm{G}$ needle. The tubes were allowed to stand for $30 \mathrm{~min}$ and then centrifuged at $800 \times \mathrm{g}$ for $15 \mathrm{~min}$ to isolate the serum. Thereafter, the sera were stored at $-20^{\circ} \mathrm{C}$ until analysis. The concentrations of glutamic oxaloacetic transaminase (GOT) and glutamic pyruvic transaminase (GTP) were determined 
by the standardized method of the Japan Society of Clinical Chemistry (JSCC method kit) (Wako Pure Chem., Osaka, Japan). Blood urea nitrogen (BUN) contents were determined by a Urase-glutamate dehydrogenase (Urease-GLDH) kit (Wako). Creatinine (CRE) levels were determined using a Jaffe kit (Wako). Triglycerides (TG) were assessed using a free glycerol blanking kit (Wako). Total cholesterol (T-Chol) was determined with a Cholesterol Oxidase-HDAOS kit (Wako).

2.6. Jejunum Villous Measurement. Intestinal samples were taken on the last day of the experiment. The intestinal sections $(2.5 \mathrm{~cm})$ from six chickens per treatment group were obtained from the jejunum at a position midway between the Meckel's diverticulum and the entrance of the bile ducts. The samples were flushed with saline, fixed in $10 \%$ buffered formalin ( $\mathrm{pH}$ 7.0), embedded with paraffin, sectioned into $3 \mu \mathrm{m}$ sections and stained with haematoxylin-eosin (IDEXX Veterinary Services, Sacramento, CA). For each intestinal section, 10 randomly selected jejunum villi heights were estimated using Image-Pro-Plus software (Media Cybernetics, Silver Spring, MD).

2.7. Peripheral Lymphocyte Proliferation Assay. To detect changes in cellular immunity, a peripheral lymphocyte proliferation assay was performed, as described previously [5]. Blood samples (5 mL per chicken) were collected and immediately transferred into aseptic capped tubes containing sodium heparin. The samples were diluted with an equal volume of Hanks' solution and carefully layered on the surface of the lymphocyte separation medium. After $15 \mathrm{~min}$ centrifugation at $800 \times \mathrm{g}$, a white cloud-like band was observed in the lymphocyte separation solution interface. The lymphocyte band was collected and washed twice with RPMI-1640 media without fetal bovine serum (FBS). After centrifugation, the pellet was resuspended in RPMI-1640 media at a concentration of $5 \times 10^{6}$ cells per $\mathrm{mL}$, and $80 \mu \mathrm{L}$ per well was incubated in 96-well tissue culture plates. Another $20 \mu \mathrm{L}$ of ConA was added to each well, and each sample was seeded in four wells. A working concentration of $5 \mu \mathrm{g} \mathrm{mL}{ }^{-1}$ ConA was used for the stimulation of lymphocytes. After $44 \mathrm{~h}$ of incubation at $39.5^{\circ} \mathrm{C}$ in the $5 \% \mathrm{CO}_{2}$ incubator, $20 \mu \mathrm{L}$ of MTT ( $5 \mathrm{mg} \mathrm{mL}^{-1}$ ) was added to each well. The plates were incubated for another $4 \mathrm{~h}$, and then $100 \mu \mathrm{L}$ of DMSO was added to each well; the plates were finally shaken for $5 \mathrm{~min}$ to completely dissolve the precipitate. Light absorbance at $570 \mathrm{~nm}$ was measured with an ELISA plate reader (Bio-Rad Laboratories Inc., Irvine, CA).

2.8. Measurement of IgA, IgG and IBD Antibodies in Serum. Total IgA and IgG concentrations in the sera were measured with the Chicken IgA and IgG ELISA Quantitation Kit (Bethyl Laboratories, Inc., Montgomery, TX) according to the manufacturer's instructions. The sera were diluted up to 500 -fold with a sample diluent solution from the kit, and read at $450 \mathrm{~nm}$ in an ELISA plate reader [21]. The antibody titer of IBDV was determined using ELISA kits (Kirkegaard \& Perry Laboratories Inc., Gaithersburg, MD), according to the manufacturer's instructions. Twenty microliters of buffer serum from each chicken was used and read at $650 \mathrm{~nm}$ in an ELISA plate reader [21].

2.9. Detection of Cytokine mRNA by Semi-Quantitative RTPCR. The mRNA expression of the cytokines IL-2, INF- $\gamma$, IL- 4 and IL- 12 was determined with a reverse transcriptional polymerase chain reaction (RT-PCR). The housekeeping gene, GAPDH, was used as an internal control. Peripheral lymphocytes were collected from the GGS-treated and untreated groups and harvested at $24 \mathrm{~h}$ after ConA stimulation. Total RNA was isolated from the tissues using the TRIzol reagent (Invitrogen Life Technologies, Carlsbad, CA), according to the manufacturer's instructions. The RNA was subsequently treated with Deoxyribonuclease I (MBI Fermentas Inc., Lithuania) to remove any genomic DNA contamination [22]. Approximately $900 \mathrm{ng}$ of total RNA was reverse-transcribed with MuLV reverse transcriptase using the GeneAmp RNA PCR Kit (Applied Biosystems, Foster, $\mathrm{CA}$ ) and oligo $\mathrm{d}(\mathrm{T}) 16$ primers. The RT-PCR primer sequences and annealing conditions for IL-2, IL-4, IL-12, INF- $\gamma$ and GAPDH are listed in Table 1. The amplified RTPCR products were subjected to electrophoresis at $100 \mathrm{~V}$ in a $2 \%$ agarose gel (Invitrogen, Carlsbad, CA) for about $30 \mathrm{~min}$ [23]. The agarose gels were stained with $0.5 \mathrm{mg} \mathrm{mL}^{-1}$ ethidium bromide Tris/borate/EDTA buffer (ICN, Costa Mesa, CA).

2.10. Statistical Analysis. The experimental data were analysed using the General Linear Model (GLM) procedure by SAS, as described previously [24]. The differences among herbal medicinal dosage and control groups were compared by least mean squares comparison. Statistical significances were based on ${ }^{*} P<.05$ and ${ }^{* *} P<.01$.

\section{Results}

3.1. Assessment of Biochemical Functions in Serum. We tested the effects of the herbal remedies on serum lipids, liver and kidney function. Feeding the chickens a diet supplemented with GGS for 16 weeks had no effect on body weight or composition (data not shown). The bioactivity indices for liver and kidney functions in the sera were measured before and after the experiment. The GOT and GPT were not significantly different between the control and tested groups; however, the BUN concentrations were significantly decreased in all GGS-treated groups $(P<.05)$, and the CRE concentration was also decreased in the middle-dose GGS-treated group $(P<.05)$, indicating that the dietary supplements of GGS modulated kidney function. The GGS containing the active component of chlorogenic acid (Figure 1) significantly reduced serum cholesterol in all three GGS-treated groups $(P<.05)$, but had no effect on the triglycerides (Table 2).

3.2. Physical Characteristics of the Jejunum. Physical changes were seen in the intestines of the birds that were given the antibiotic growth promoter and health factor. The jejunum histology and villous length of chickens fed a diet with or 
TABLE 1: Oligonucleotide primer sets used for semi-quantitative RT-PCR.

\begin{tabular}{|c|c|c|c|c|c|}
\hline RNA target & Primer sets & Oligonucleotide sequence & Annealing temperature $\left({ }^{\circ} \mathrm{C}\right)$ & Product size $(\mathrm{bp})$ & Accession no. \\
\hline \multirow{2}{*}{ INF- $\gamma$} & $\mathrm{F}$ & 5' $^{\prime}$-AGCTGACGGTGGACCTATTA-3' & \multirow{2}{*}{56} & \multirow{2}{*}{259} & \multirow{2}{*}{ NM_205149 } \\
\hline & $\mathrm{R}$ & 5'-GGCTTTGCGCTGGATTCTC-3' & & & \\
\hline \multirow{2}{*}{ IL-2 } & $\mathrm{F}$ & $5^{\prime}$-CTGGGACCACTGTATGCTCT-3' & \multirow{2}{*}{55} & \multirow{2}{*}{256} & \multirow{2}{*}{ AF017645 } \\
\hline & $\mathrm{R}$ & $5^{\prime}$-CACCAGTGGGAAACAGTATC-3' & & & \\
\hline \multirow{2}{*}{ IL-4 } & $\mathrm{F}$ & 5'-ACCCAGGGCATCCAGAAG-3' & \multirow{2}{*}{55} & \multirow{2}{*}{258} & \multirow{2}{*}{ AJ621735 } \\
\hline & $\mathrm{R}$ & 5'-CAGTGCCGGCAAGAAGTT-3' & & & \\
\hline \multirow{2}{*}{ IL-12 } & $\mathrm{F}$ & 5'-AGACTCCAATGGGCAAATGA-3' & \multirow{2}{*}{56} & \multirow{2}{*}{244} & \multirow{2}{*}{ NM_213571 } \\
\hline & $\mathrm{R}$ & $5^{\prime}$-CTCTTCGGCAAATGGACAGT-3' & & & \\
\hline \multirow{2}{*}{ GAPDH } & $\mathrm{F}$ & 5'-GGTGGTGCTAAGCGTGTTAT-3' & \multirow{2}{*}{56} & \multirow{2}{*}{264} & \\
\hline & $\mathrm{R}$ & 5'-ACСTCTGTCATCTCTCCACA-3' & & & \\
\hline
\end{tabular}

TABLE 2: The effects of different supplemental dosages of GGS on serum parameters in chickens.

\begin{tabular}{|c|c|c|c|c|c|}
\hline \multirow{2}{*}{ Item } & \multirow{2}{*}{ Control group } & \multicolumn{3}{|c|}{ Treated group ${ }^{a}$} & \multirow{2}{*}{ SE } \\
\hline & & $\mathrm{GGS}_{\mathrm{L}}$ & $\mathrm{GGS}_{\mathrm{M}}$ & $\mathrm{GGS}_{\mathrm{H}}$ & \\
\hline GGS Dose $(\%, w / w)$ & 0 & $0.5 \%$ & $1 \%$ & $2 \%$ & \\
\hline $\operatorname{GOT}\left(\mathrm{UL}^{-1}\right)$ & 195.3 & 171.3 & 183.8 & 182.5 & 13.4 \\
\hline $\operatorname{GPT}\left(\mathrm{UL}^{-1}\right)$ & 7.7 & 6.8 & 7.7 & 6.8 & 0.8 \\
\hline Cholesterol $\left(\mathrm{md} \mathrm{dL}^{-1}\right)$ & 109.3 & $90.8^{*}$ & $83.8^{*}$ & $80.7^{*}$ & 5.9 \\
\hline Triglycerides $\left(\mathrm{md} \mathrm{dL}^{-1}\right)$ & 27.8 & 33.5 & 21.3 & 24.8 & 6.9 \\
\hline $\mathrm{BUN}\left(\mathrm{md} \mathrm{dL}^{-1}\right)$ & 2.4 & $1.9^{*}$ & $1.6^{*}$ & $1.6^{*}$ & 0.2 \\
\hline Creatinine (md dL $\left.{ }^{-1}\right)$ & 0.28 & 0.23 & $0.20^{*}$ & 0.25 & 0.02 \\
\hline
\end{tabular}

${ }^{a} \mathrm{GGS}_{\mathrm{L}}$ : low dose of GGS; GGS $\mathrm{M}$ : medium dose of GGS; GGS $\mathrm{H}$ : high dose of GGS.

* Significant difference $(P<.05$ versus control group).

without GGS at 16 weeks are shown in Figure 2. The villous length was significantly higher in the GGS-treated group than in the control group $(1250 \pm 53$ versus $1603 \pm 72 \mu \mathrm{m}$; $P<.05)$, indicating that dietary supplementation with GGS is beneficial to the health of the chicken.

3.3. Peripheral Lymphocyte Proliferation in Response to GGS. To investigate the effects of GGS on peripheral lymphocyte proliferation, we collected peripheral lymphocytes from chickens treated with different dosages of orally administered GGS, and treated them with or without ConA in vitro. Proliferation was measured via the MTT assay, and changes in the proliferation ratio (ConA+/ConA-) are summarized in Table 3. At Weeks 8, 12 and 16, peripheral lymphocyte proliferation in the $\mathrm{GGS}_{\mathrm{M}}$-treated group was slightly increased; however, proliferation in the $\mathrm{GGS}_{\mathrm{H}}$-treated group was significantly higher than in the control group, by 2-3fold $(P<.05)$.

3.4. Systemic Antibody Response. To evaluate the effects of GGS on the serum antibodies, the presence of natural antibodies to IgA (Figure 3(a)) and IgG (Figure 3(b)) in the sera of GGS-treated and untreated birds was assessed. In the $\mathrm{GGS}_{\mathrm{L}}$-treated group only, the sera contained significantly higher levels of IgA antibodies in the females than in the control group $(P<.05)$ (Figure 3(a)). However, there was no
TABLe 3: The effects of supplemental GGS on peripheral lymphocyte proliferation in chickens of different ages.

\begin{tabular}{lcccc}
\hline & & \multicolumn{3}{c}{$\begin{array}{c}\text { Lymphocyte proliferation ratio } \\
\text { Group }\end{array}$} \\
& & Dose $(\%, w / w)$ & (ConA+/ConA-) \\
& & 8 weeks & 12 weeks & 16 weeks \\
\hline Control & 0 & 1.90 & 2.13 & 1.87 \\
GGS $_{\mathrm{L}}$ & 0.5 & 1.77 & 2.18 & 1.72 \\
$\mathrm{GGS}_{\mathrm{M}}$ & 1.0 & 2.40 & 2.68 & 2.79 \\
$\mathrm{GGS}_{\mathrm{H}}$ & 2.0 & $3.09^{*}$ & $3.76^{*}$ & $5.24^{*}$ \\
$\mathrm{SE}$ & & 0.34 & 0.31 & 0.52 \\
\hline
\end{tabular}

${ }^{a} G_{\text {GS }}$ : Low dose of GGS; GGS $_{\mathrm{M}}$ : medium dose of GGS; $\mathrm{GGS}_{\mathrm{H}}$ : high dose of GGS.

* Significant difference $(P<.05$ versus control group).

significant difference in IgG antibodies between the groups (Figure 3(b)).

3.5. Enhanced IBD Antibody Titer in Response to GGS. Changes in the IBD antibody titers in response to GGS are listed in Table 4. In general, the antibody titers of all treatment groups at each time point were higher than those of the control group, and the serum IBD antibody titers in all groups at Week 16 were lower than those at Week 8. After vaccination, the serum antibody titers in the lowdosage $\mathrm{GGS}_{\mathrm{L}}$-treated groups were significantly higher than those of the control group $(P<.05)$ and other treatment groups at Week 8. At Week 16, the IBD antibody titers of $\mathrm{GGS}_{\mathrm{L}}$ and GGSM groups were significantly higher than those of the control group $(P<.05)$.

3.6. Cytokine Gene Expression. Changes in cytokine expression at Week 8 are shown in Figure 4. In the IL-2 and INF- $\gamma$ networks, the IL-2 and INF- $\gamma$ mRNA levels of the normal control group were low; ConA increased their expression. GGS increased IL-2 expression in the medium-dose groups $(P<.05)$, but significantly increased IL-2 in the high-dose group $(P<.01)$. GGS increased INF- $\gamma$ expression in a dosedependent manner in all groups except the low-dose group, which demonstrated suppressed INF- $\gamma$ expression. In the IL4 and IL-12 network, the expression of IL-4 and IL-12 was 


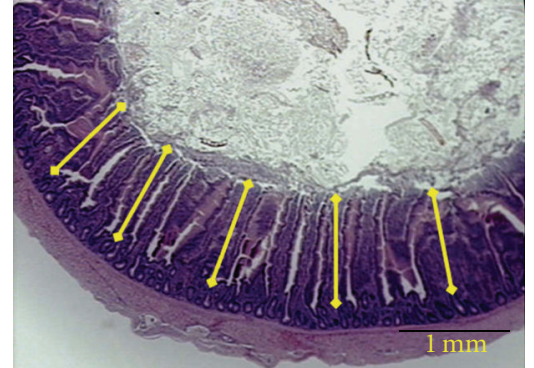

(a)

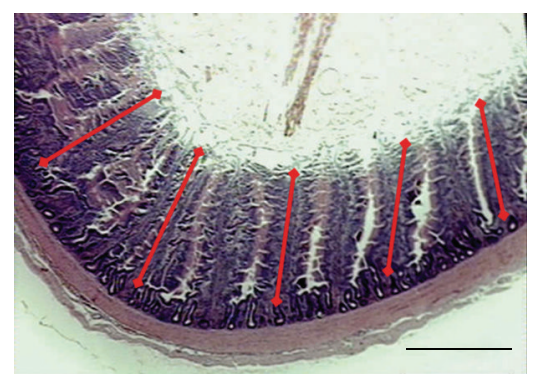

(b)

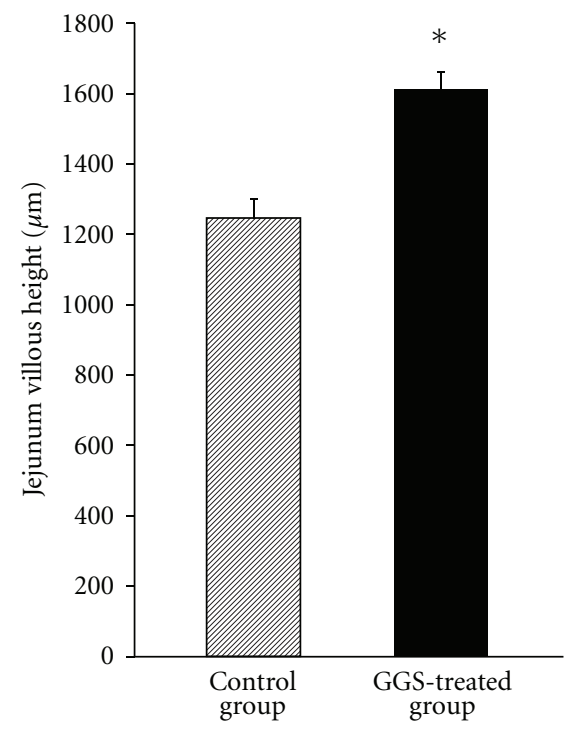

(c)

FIGURE 2: Effect of GGS on jejunum. Jejunum histology and villous length of chickens fed a basal diet without GGS (control) (a) compared to those fed a basal diet with $0.5 \%$ GGS (treatment) (b). For each intestinal section, the jejunum villous height was estimated for at least 10 individual villi in the control and GGS-treated groups, as shown by the yellow and red lines, respectively. The scale bar represents $1 \mathrm{~mm}$. (c) Mean \pm SE of jejunum villous height $(\mu \mathrm{m})$ in control and treated groups. ${ }^{*} P<.05$.

TABLE 4: The effects of supplemental GGS on the IBD antibody titer $\left(\times 10^{3}\right)$ in chickens of different ages.

\begin{tabular}{lccc}
\hline \multirow{2}{*}{ Group $^{\mathrm{a}}$} & \multirow{2}{*}{ Dose $(\%, \mathrm{w} / \mathrm{w})$} & \multicolumn{2}{c}{ IBD antibody titer $\left(\times 10^{3}\right)$} \\
& & 8 weeks & 16 weeks \\
\hline Control & 0 & 5.892 & 5.080 \\
$\mathrm{GGS}_{\mathrm{L}}$ & 0.5 & $11.006^{*}$ & $8.191^{*}$ \\
$\mathrm{GGS}_{\mathrm{M}}$ & 1.0 & 9.935 & $9.819^{*}$ \\
$\mathrm{GGS}_{\mathrm{H}}$ & 2.0 & 6.831 & 6.640 \\
$\mathrm{SE}$ & & 1.461 & 0.968 \\
\hline
\end{tabular}

${ }^{\mathrm{a}} \mathrm{GGS}_{\mathrm{L}}$ : low dose of GGS; $\mathrm{GGS}_{\mathrm{M}}$ : medium dose of GGS; GGS $\mathrm{H}$ : high dose of GGS.

* Significant difference $(P<.05$ versus control group).

low in the normal control group. ConA treatment increased the level of IL-4 but not IL-12. We also observed that IL-4 was down-regulated in the low- and medium-dose groups, and slightly increased in the high-dose GGSH-treated group. IL-12 expression was significantly increased in the high-dose GGS-treated group $(P<.01)$.

\section{Discussion}

GGS enhanced the IBD antibody titer at a low dose, and promoted peripheral lymphocyte proliferation at a high dose. GGS regulated the expression of IL-2, INF- $\gamma$, IL-4 and IL-12 in the ConA-stimulated peripheral T lymphocytes.

Physical changes were observed in the intestines of birds that were given the antibiotic growth promoter and health factor. The growth promoter is known to inhibit normal early microbial proliferation and, hence, the competition for essential nutrients during the gut maturation process in chickens [25]. In our study, GGS increased the length of the jejunum (Figure 2), indicating that GGS could improve antimicrobial proliferation and increase nutrition absorption. GGS was also found to protect kidney function and to decrease cholesterol in GGS-treated groups for a long period of time (Table 2). All of these data suggest that GGS could improve the health of an organism.

A traditional control strategy for IBD in broilers has involved protection via passive immunization [4]. However, traditional inactivated or attenuated vaccines do not provide enough protection against these antigenic variants, which are very virulent (vv) IBDV [26]. Improving the effectiveness of the IBD vaccine is, therefore, an important issue. According to our data, the low dosage GGS-treated group showed enhanced IBD antibody titers at Week 8. The low and medium dosage groups also had significantly higher IBD antibody titers than the control group at Week 16 (Table 4). In a previous report, 1-day-old chickens were fed a diet with or without ascorbic acid and vaccinated against IBD at 7 days of age, and both groups were then challenged orally with $4 \times 10^{5}$ IBDV viral particles at 21 days of age. At 21 days of age (14 days post-vaccination) and 31 days of age (10 days post-challenge), the number of anti-IBDV IgG antibody secreting cells were significantly higher in the ascorbic acid supplemented group than in the control group [27]. A similar study also revealed that orally administered $2 \%$ L-arginine elicited a higher antibody titer after IBDV vaccination, and increased protection rate after IBDV challenge, when compared with the control group [28]. These 

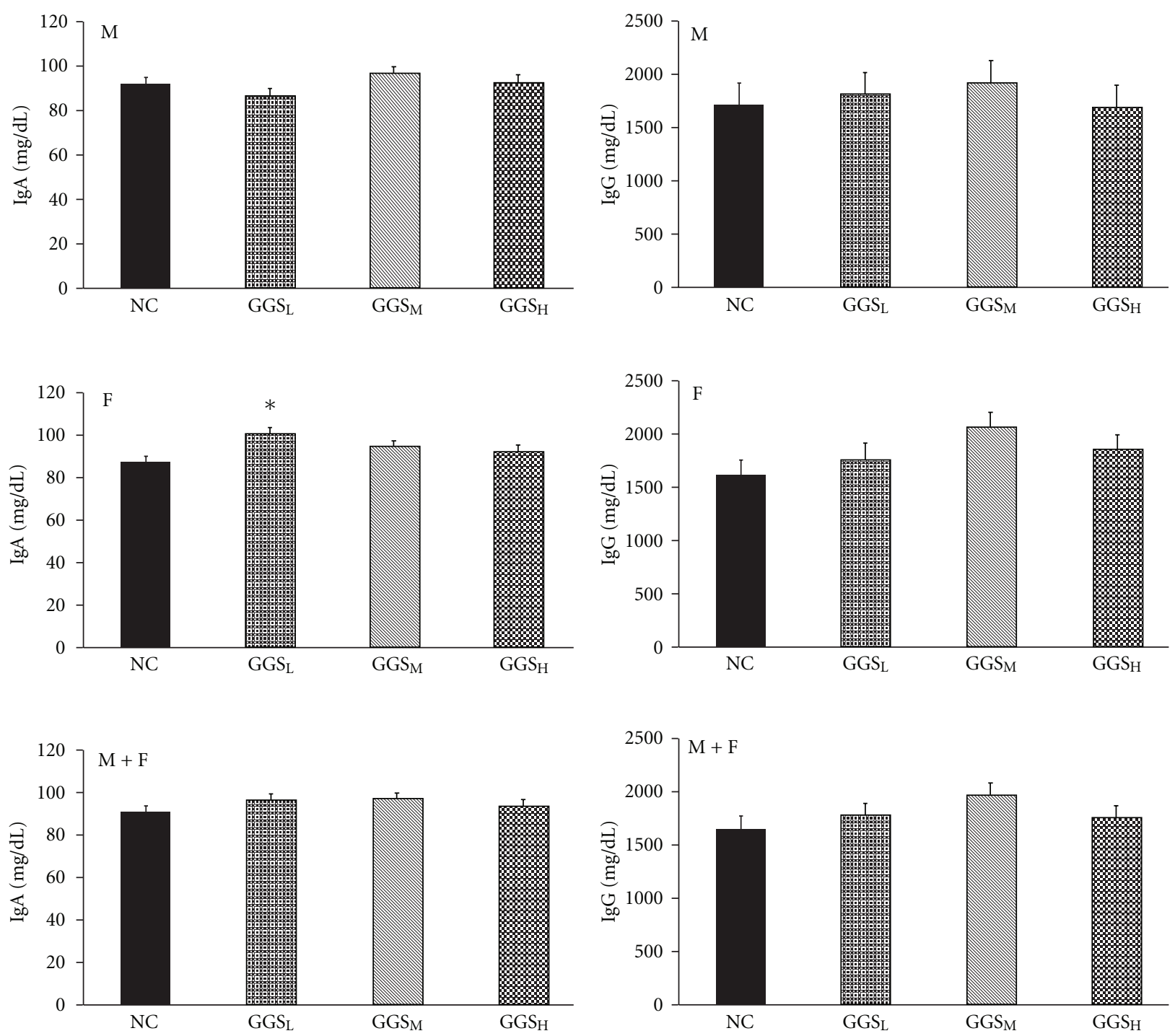

(a)

(b)

FIGURE 3: Effect of GGS on serum IgA (a) and IgG (b). The negative control (NC) group was fed with a basal diet without GGS. The levels of serum IgA and $\operatorname{IgG}\left(\mathrm{mg} \mathrm{dL}^{-1}\right)$ in the $0.5,1$ and $2 \%$ GGS-treated native chicken groups are shown as $\mathrm{GGS}_{\mathrm{L}}, \mathrm{GGS}_{\mathrm{M}}$ and GGS $\mathrm{H}_{\mathrm{H}}$, respectively. Blood samples were collected at 16 weeks of age. Upper panel (M): Data from male chickens in each group. Middle panel (F): Data from female chickens in each group. Lower panel $(\mathrm{M}+\mathrm{F})$ : Combined male and female data. The asterisks represent significant differences $(P<.05)$ compared with the respective control groups.

results suggested that increasing the anti-IBDV antibody titer response to IBDV vaccination would increase the protection efficiency against IBDV infection. Most pathogens invade the body of their host through mucosal surfaces, especially those lining the gastrointestinal, respiratory and genitourinary tracts. Despite their phylogenetic distance, both mammals and bird species use polymeric $\operatorname{IgA}(\mathrm{pIgA})$, which is produced by plasma cells in the lamina propria underlying the mucosal epithelia [29], as the primary immunological defense against such infections. It is interesting to note that in our study, a low dosage of GGS increased the level of IgA in the serum of female chickens (Figure 3), indicating that a low dosage of GGS could increase the primary immunological defense in mucosal epithelia. We do not yet understand why this phenomenon only appeared in the females.

IBD causes bursal follicular lymphoid depletion, leading to significant reduction in humoural immune responses. IBDV infection apparently affects immature or precursor $\mathrm{B}$ cells to a greater extent than mature B-lymphocytes. The disease is a major problem in concentrated poultry production areas throughout the world. However, it is often not recognized because of its often subclinical presentation. Affected chickens have reduced antibody response to vaccinations, strong postvaccination reactions and increased susceptibility to concurrent or secondary infections [27]. Traditional IBD vaccines have focused on stimulating the B cells. However, recent studies that have focused on the 


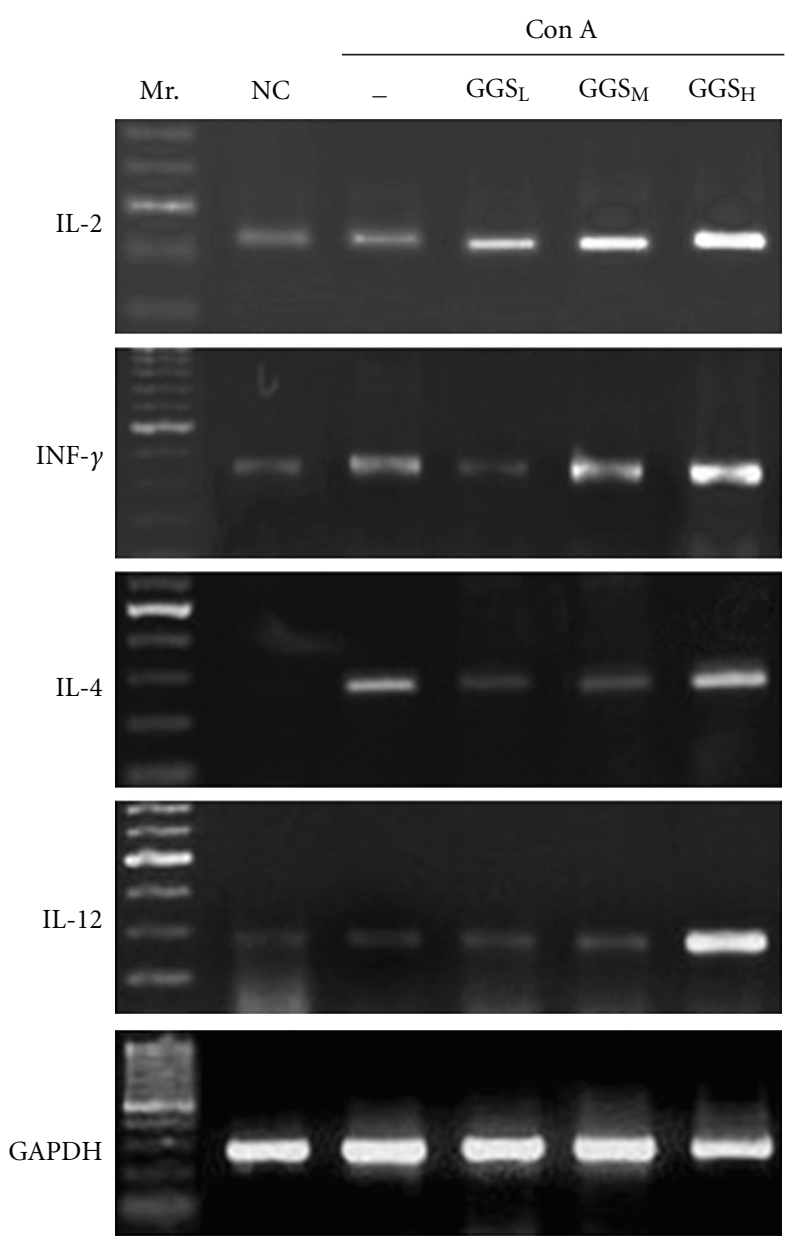

(a)

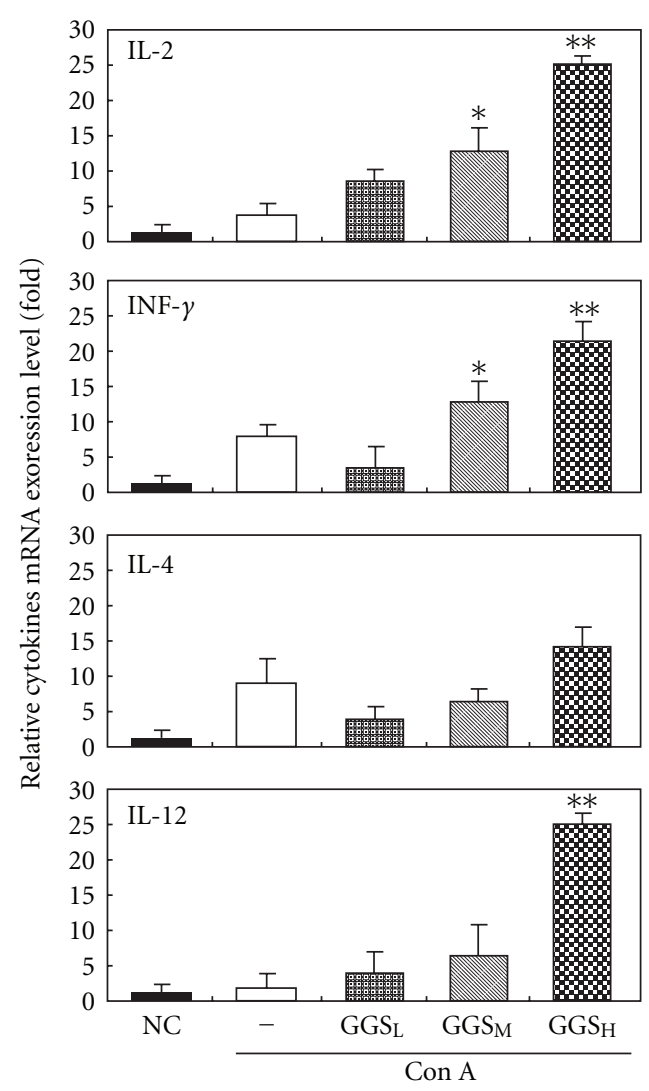

(b)

FIGURE 4: Quantitative analysis of IL-2, INF-, IL-4 and IL-12 mRNA expression in cultured chicken peripheral lymphocytes treated with different GGS doses at $24 \mathrm{~h}$ after ConA stimulation. (a) Representation of mRNA expression by semi-quantitative RT-PCR analysis. Mr.: 100-bp ladder of DNA markers; NC: normal cultured chicken peripheral lymphocytes (Week 8) without ConA stimulation; -: no GGS; $\mathrm{GGS}_{\mathrm{L}}$ : low-dose GGS treatment group; $\mathrm{GGS}_{\mathrm{M}}$ : medium-dose GGS treatment group; $\mathrm{GGS}_{\mathrm{H}}$ : high-dose GGS treatment group. The results are representative of three experiments. (b) The relative mRNA expression levels in control and different GGS-treated groups were quantified by a densitometer. The signal from GAPDH RT-PCR products in each sample was used as an internal control in each mRNA calculation. ${ }^{*} P<.05 ;{ }^{* *} P<.01$.

importance of $\mathrm{T}$ cells in IBDV pathogenesis, have shown that cell-mediated immunity may be more important in IBDV infections than previously thought $[30,31]$. Our data show that a high dose of GGS can improve peripheral $\mathrm{T}$ lymphocyte proliferation in response to ConA stimulation and can increase the proliferation rate of these cells in a timedependent manner beginning at Week 8 (Table 3 ).

Interleukin-2 (IL-2), initially known as a T-cell growth factor, is a powerful immuno-regulatory lymphokine that is produced by lectin- or antigen-activated T cells $[8,32,33]$. It is secreted by mature T lymphocytes upon stimulation, and is constitutively secreted by certain T-cell lymphoma cell lines. Chicken IL-2 (ChIL-2) may enhance immunity against avian pathogens, which would introduce a new weapon for the control of infectious diseases in poultry. The administration of the IBD vaccine with ChIL-2 provided better protection than vaccination alone [8]. Previous reports showed that the simultaneous injection of chicken IL-2 plasmid DNA with the IBD vaccine significantly increased protection after challenge with the virulent strain $[32,33]$. These results strongly indicate that the efficacy of the avian DNA vaccine could be modulated by the co-administration of a plasmid encoding ChIL-2. In this study, we further demonstrated that a high-dose of GGS strongly enhanced ConA-induced ChIL2. Therefore, GGS could improve the efficiency of the IBD vaccine. Furthermore, immune cells and immune molecules can mutually regulate one another and form many immune regulation networks. The IL-2-IFN- $\gamma$-NKC system is one such immune regulation network. In this network, IL-2 plays an important role in regulating the generation of IFN- $\gamma$ and the activity of natural killer cells (NKC). IFN- $\gamma$ also participates in the immune response mediated by $\mathrm{T}$ cells, B cells and other immune cells [34]. IFN- $\gamma$ severely restricts virus replication and can even cure persistently infected bovine 


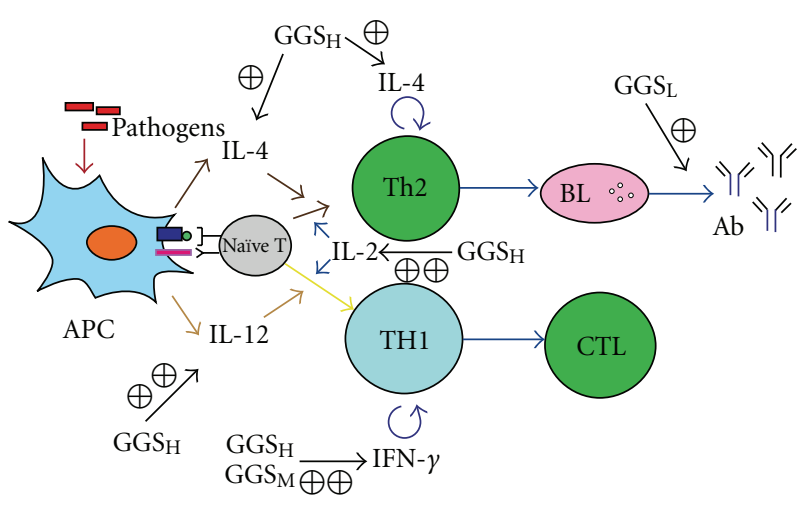

FIGURE 5: Proposed mechanism of GGS functions in immunity enhancement. High-dose of GGS $\left(\mathrm{GGS}_{\mathrm{H}}\right)$ administration will increase IL-2, IL-4 and IL-12 expression from antigen presenting cells (APC) to stimulate naïve T cells differentiation. Administration of a medium dose of GGS $\left(\mathrm{GGS}_{\mathrm{M}}\right)$ as well as $\mathrm{GGS}_{\mathrm{H}}$ will enhance IFN- $\gamma$ expression to stimulate T-helper 1 (Th1) cells differentiation and cytotoxic T lymphocytes (CTL) function. Administration of a low-dose of $\left(G_{G S}\right)$ will further increase B lymphocytes (BL) producing specific antibodies.

epithelial cells [35]. Our study showed that the medium- and high-dose GGS-treated groups not only exhibited increased expression of IL-2 mRNA, but also increased expression of IFN- $\gamma$ mRNA (Figure 4). Chlorogenic acid is the most abundant compound in the GGS. In the previous study, it was found that chlorogenic acid could enhance the activity of human lymphocyte proliferation and IFN- $\gamma$ secretion [36]. Thus, it is proposed that GGS strengthened immunity via the mechanism outlined in Figure 5.

In mammals, it has been known for some time that the balance between the Th1 and Th2 lymphocyte subsets determines susceptibility to some disease states. Thus, an unusually dominant Th1 response is often associated with autoimmunity, while improper development of Th2 immunity can lead to allergic diseases [37]. Chicken Th2 cells are necessary to induce the humoural response to combat parasite invasion [38]. As in mammals, the chicken genome contains a cluster of Th2 cytokine genes containing IL-4 and other cytokines that are expressed in lymphoid tissues. Activation of this gene cluster is associated with downregulating the inflammatory (Th1) response and, as a result, drives Th2 cell development [38]. Unlike IL-4, IL-12 is able to facilitate the proliferation and activation of Thl cells and the production of IL-2 and IFN- $\gamma$ [39]. IL-12 induces IFN$\gamma$ synthesis by neonatal CD4 T-cells. Additionally, IL-2 can further synergise with IL-12 to trigger IFN- $\gamma$ production $[40,41]$. Our data demonstrate that GGS-treated chickens produced more IL-12 than IL-4, and that IL-2 and INF- $\gamma$ were also up-regulated. The results reveal that GGS can skew the lymphocyte subset development towards Th1 rather than Th2 cells.

In conclusion, our results show that GGS-enhanced cellmediated immunity and assisted the IBD vaccine, strengthening the anti-viral functions. Since the chicken's immune system is similar to that of mammals, chickens provide an attractive model system to study the effectiveness of GGS supplements in controlling diseases in livestock and human beings. Nevertheless, additional investigations are required to determine the potential clinical utility of GGS as an immunopotentiator in infant vaccination programmes. The pharmaceutical technology of TCM as applied in animal health care is relatively simple, and its production costs are relatively low.

\section{Funding}

Council of Agriculture [95AS-5.1.2-LI-L1(3), partial], National Science Council, and the Ministry of Education, Taiwan, Republic of China, under the ATU plan (NSC-972313-B-005-004-MY3).

\section{Acknowledgment}

The authors would like to thank Dr Jeffrey Conrad for critically reading the manuscript. C.-M. Hung, K.-Y. Chong, and H.-L. Chen contributed equally to this work.

\section{References}

[1] D. Wang, Y. Hu, J. Sun, X. Kong, B. Zhang, and J. Liu, "Comparative study on adjuvanticity of compound Chinese herbal medicinal ingredients," Vaccine, vol. 23, no. 28, pp. 3704-3708, 2005.

[2] C.-C. Yeh, C.-C. Lin, S.-D. Wang et al., "Protective and immunomodulatory effect of Gingyo-san in a murine model of acute lung inflammation," Journal of Ethnopharmacology, vol. 111, no. 2, pp. 418-426, 2007.

[3] C.-H. Hsu, K.-C. Hwang, C.-L. Chao et al., "An evaluation of the additive effect of natural herbal medicine on SARS or SARS-like infectious diseases in 2003: a randomized, double-blind, and controlled pilot study," Evidence-Based Complementary and Alternative Medicine, vol. 5, no. 3, pp. 355-362, 2008.

[4] L. W. Fussell, "Poultry industry strategies for control of immunosuppressive diseases," Poultry Science, vol. 77, no. 8, pp. 1193-1196, 1998.

[5] X. Kong, Y. Hu, R. Rui, D. Wang, and X. Li, "Effects of Chinese herbal medicinal ingredients on peripheral lymphocyte proliferation and serum antibody titer after vaccination in chicken," International Immunopharmacology, vol. 4, pp. 975-982, 2004.

[6] Y. M. Saif, "Infectious bursal disease and hemorrhagic enteritis," Poultry Science, vol. 77, no. 8, pp. 1186-1189, 1998.

[7] M. M. Nagarajan and F. S. B. Kibenge, "Infectious bursal disease virus: a review of molecular basis for variations in antigenicity and virulence," Canadian Journal of Veterinary Research, vol. 61, no. 2, pp. 81-88, 1997.

[8] Y. Liu, Y. Wei, X. Wu, and L. Yu, "Preparation of ChIL-2 and IBDV VP2 fusion protein by baculovirus expression system," Cellular \& Molecular Immunology, vol. 2, no. 3, pp. 231-235, 2005.

[9] Y. S. Wu, Y. C. Chen, and Y. C. Yan, "Studies in immunization of infectious bursal disease," Journal of the Chinese Society of Veterinary Science, vol. 9, pp. 125-132, 1983.

[10] M. Kurokawa, J.-I. Yamamura, Z. Li et al., "Antipyretic activity of Gingyo-san, a traditional medicine, in influenza 
virus-infected mice," Chemical and Pharmaceutical Bulletin, vol. 46, no. 9, pp. 1444-1447, 1998.

[11] M. Kobayashi, S. M. Davis, T. Utsunomiya, R. B. Pollard, and F. Suzuki, "Antiviral effect of gingyo-san, a traditional chinese herbal medicine, on influenza A2 virus infection in mice," American Journal of Chinese Medicine, vol. 27, no. 1, pp. 53 62, 1999.

[12] Q. M. Chen, L. J. Huang, and W. Wang, "Clinical application and pharmacological experiment study of yingqiao powder," Journal of Traditional Chinese Medicine, vol. 9, pp. 36-39, 2003.

[13] J. R. Xiao, H. J. Wu, Y. Guo, H. M. Huang, S. H. Qiu, and G. H. Guo, "A comparative study on the pharmacodynamic effects of different preparations of yinqiao powder on bacteria and viruses," Journal of Traditional Chinese Medicine, vol. 23, pp. 15-18, 2003.

[14] Y. Shi, R. B. Shi, B. Liu, and Y. R. Lu, "Studies on antiviral flavonoids in yinqiaosan powder," China Journal of Chinese Materia Medica, vol. 26, pp. 320-323, 2001.

[15] S.-T. Kao, C.-C. Yeh, C.-C. Hsieh et al., "The Chinese medicine Bu-Zhong-Yi-Qi-Tang inhibited proliferation of hepatoma cell lines by inducing apoptosis via $\mathrm{G}_{0} / \mathrm{G}_{1}$ arrest," Life Sciences, vol. 69, no. 13, pp. 1485-1496, 2001.

[16] C.-M. Chen, H.-L. Chen, T. H.-C. Hsiau et al., "Methylation target array for rapid analysis of $\mathrm{CpG}$ island hypermethylation in multiple tissue genomes," American Journal of Pathology, vol. 163, no. 1, pp. 37-45, 2003.

[17] H.-L. Chen, C.-C. Yen, T.-C. Tsai et al., "Production and characterization of human extracellular superoxide dismutase in the methylotrophic yeast Pichia pastoris," Journal of Agricultural and Food Chemistry, vol. 54, no. 21, pp. 8041-8047, 2006.

[18] National Research Council, Nutrient Requirement of Poultry, National Academy Press, Washington, DC, USA, 9th edition, 1994.

[19] C. M. Chen, W. T. K. Cheng, Y. C. Chang, T. J. Chang, and H. L. Chen, "Growth enhancement of fowls by dietary administration of recombinant yeast cultures containing enriched growth hormone," Life Science, vol. 67, pp. 2103-2115, 2000.

[20] S.-C. Wu, H.-L. Chen, C.-C. Yen et al., "Recombinant porcine lactoferrin expressed in the milk of transgenic mice enhances offspring growth performance," Journal of Agricultural and Food Chemistry, vol. 55, no. 12, pp. 4670-4677, 2007.

[21] H. L. Chen, Y. W. Lai, C. C. Yen, Y. Y. Lin, C. Y. Lu, S. H. Yang et al., "Production of recombinant porcine lactoferrin exhibiting antibacterial activity in methylotrophic yeast, Pichia pastoris," Journal of Molecular Microbiology and Biotechnology, vol. 8, pp. 141-149, 2004.

[22] H.-L. Chen, J.-Y. Huang, T.-W. Chu et al., "Expression of VP1 protein in the milk of transgenic mice: as a potential oral vaccine protects against enterovirus 71 infection," Vaccine, vol. 26, no. 23, pp. 2882-2889, 2008.

[23] H. L. Chen, J. Y. Huang, T. W. Chu, T. C. Tsai, C. M. Hung, C. C. Lin et al., "Recombinant porcine lactoferrin expressed in the milk of transgenic mice protects neonatal mice from a lethal challenge with enterovirus type 71," Vaccine, vol. 26, pp. 891-898, 2008.

[24] C.-M. Chen, C.-H. Wang, S.-C. Wu, C.-C. Lin, S.-H. Lin, and W. T. K. Cheng, "Temporal and spatial expression of biologically active human factor VIII in the milk of transgenic mice driven by mammary-specific bovine $\alpha$-lactalbumin regulation sequences," Transgenic Research, vol. 11, no. 3, pp. 257-268, 2002.
[25] R. D. Miles, G. D. Butcher, P. R. Henry, and R. C. Littell, "Effect of antibiotic growth promoters on broiler performance, intestinal growth parameters, and quantitative morphology," Poultry Science, vol. 85, pp. 476-485, 2006.

[26] L. Yu, J. R. Li, Y. W. Huang, J. Dikki, and R Deng, "Molecular characteristics of full-length of genomic segment A of three infectious bursal disease viruses in China: two attenuated and a field virulent strain," Avian Diseases, vol. 45, pp. 862-874, 2001.

[27] C. C. Wu, T. Dorairajan, and T. L. Lin, "Effect of ascorbic acid supplementation on the immune response of chickens vaccinated and challenged with infectious bursal disease virus," Veterinary Immunology and Immunopathology, vol. 74, pp. 145-152, 2000.

[28] C. Tayade, M. Koti, and S. C. Mishra, "L-Arginine stimulates intestinal intraepithelial lymphocyte functions and immune response in chickens orally immunized with live intermediate plus strain of infectious bursal disease vaccine," Vaccine, vol. 24, pp. 5473-5480, 2006.

[29] K. Mostov and C. S. Kaetzel, "Ig transport and the polymeric immunoglobulin receptor," in Mucosal Immunology, P. L. Ogra, J. Mestecky, M. E. Lamm, W. Strober, J. Bienenstock, and J. R. McGhee, Eds., Academic Press, San Diego, Calif, USA, 1999.

[30] S. Rautenschlein, H.-Y. Yeh, M. K. Njenga, and J. M. Sharma, "Role of intrabursal T cells in infectious bursal disease virus (IBDV) infection: $\mathrm{T}$ cells promote viral clearance but delay follicular recovery," Archives of Virology, vol. 147, no. 2, pp. 285-304, 2002.

[31] A. E. Williams and T. F. Davison, "Enhanced immunopathology induced by very virulent infectious bursal disease virus," Avian Pathology, vol. 34, no. 1, pp. 4-14, 2005.

[32] I. Eldaghayes, L. Rothwell, A. Williams et al., "Infectious bursal disease virus: strains that differ in virulence differentially modulate the innate immune response to infection in the chicken bursa," Viral Immunology, vol. 19, no. 1, pp. 83-91, 2006.

[33] J. Li, X. Liang, Y. Huang et al., "Enhancement of the immunogenicity of DNA vaccine against infectious bursal disease virus by co-delivery with plasmid encoding chicken interleukin 2," Virology, vol. 329, no. 1, pp. 89-100, 2004.

[34] A. Jewett and B. Bonavida, "Target-induced inactivation and cell death by apoptosis in a subset of human NK cells," Journal of Immunology, vol. 156, no. 3, pp. 907-915, 1996.

[35] Z. D. Zhang, G. Hutching, P. Kitching, and S. Alexandersen, "The effects of gamma interferon on replication of foot-andmouth disease virus in persistently infected bovine cells," Archives of Virology, vol. 147, no. 11, pp. 2157-2167, 2002.

[36] L.-C. Chiang, L. T. Ng, W. Chiang, M.-Y. Chang, and C.-C. Lin, "Immunomodulatory activities of flavonoids, monoterpenoids, triterpenoids, iridoid glycosides and phenolic compounds of Plantago species," Planta Medica, vol. 69, no. 7, pp. 600-604, 2003.

[37] E. S. Hwang, S. J. Szabo, P. L. Schwartzberg, and L. H. Glimcher, "T helper cell fate specified by kinase-mediated interaction of T-bet with GATA-3," Science, vol. 307, no. 5708, pp. 430-433, 2005.

[38] S. Avery, L. Rothwell, W. D. Degen et al., "Characterization of the first non-mammalian T2 cytokine gene cluster: the cluster contains functional single-copy genes for IL-3, IL-4, IL-13, and GM-CSF, a gene for IL-5 that appears to be a pseudogene, and a gene encoding another cytokine-like transcript, KK34," 
Journal of Interferon \& Cytokine Research, vol. 24, pp. 600-610, 2004.

[39] S. M. Lee, Y. Suen, J. Qian, E. Knoppel, and M. S. Cairo, "The regulation and biological activity of interleukin 12," Leukemia and Lymphoma, vol. 29, no. 5-6, pp. 427-438, 1998.

[40] M. A. Masri, "The mosaic of immunosuppressive drugs," Molecular Immunology, vol. 39, no. 17-18, pp. 1073-1077, 2003.

[41] F. E. Fox, M. Kubin, M. Cassin et al., "Retinoids synergize with interleukin-2 to augment IFN- $\gamma$ and interleukin-12 production by human peripheral blood mononuclear cells," Journal of Interferon and Cytokine Research, vol. 19, no. 4, pp. 407-415, 1999. 


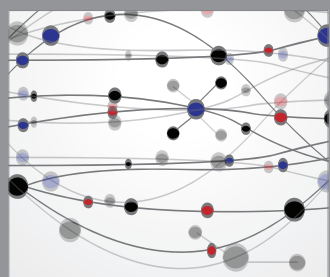

The Scientific World Journal
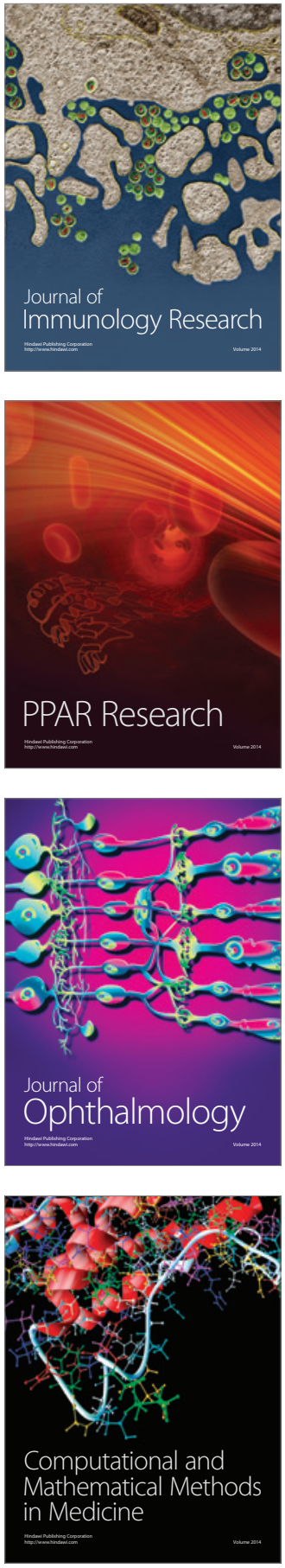

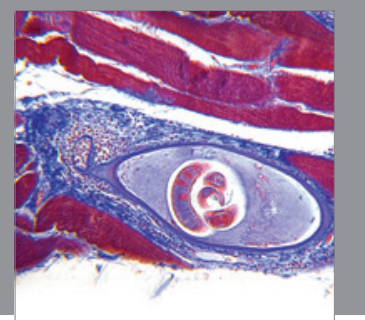

Gastroenterology

Research and Practice
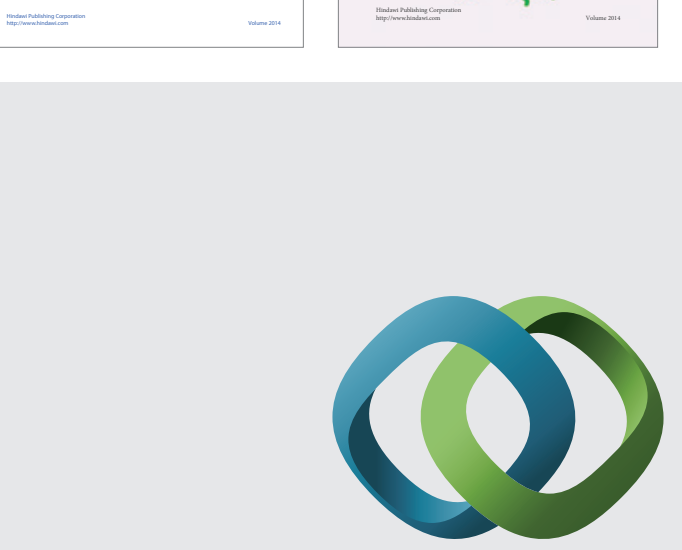

\section{Hindawi}

Submit your manuscripts at

http://www.hindawi.com
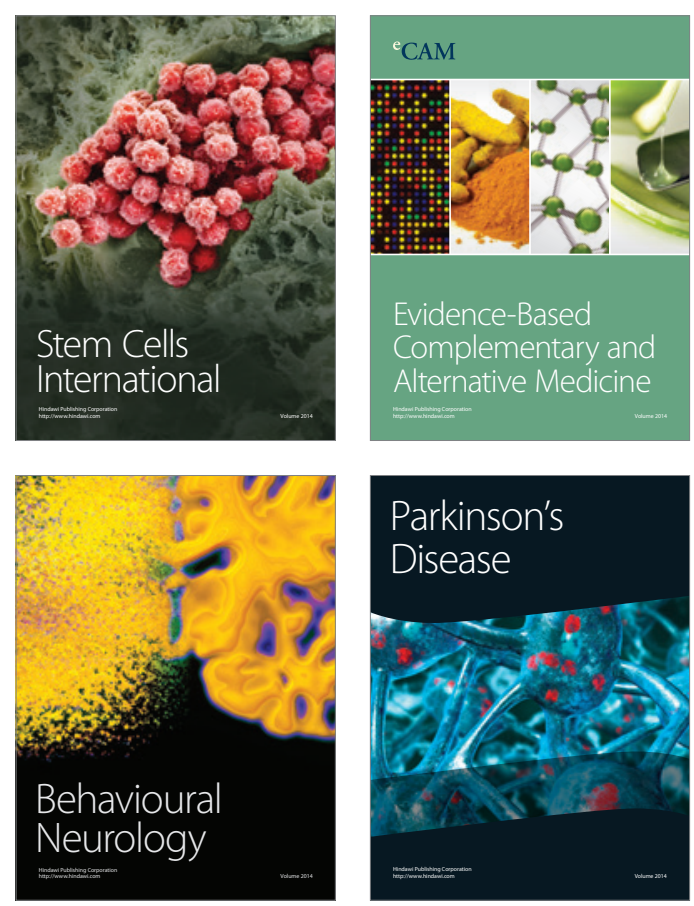

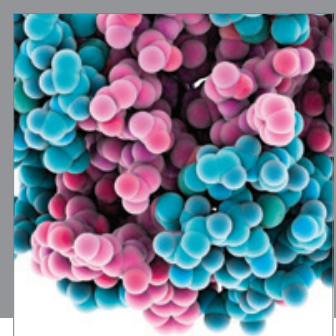

Journal of
Diabetes Research

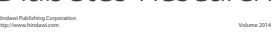

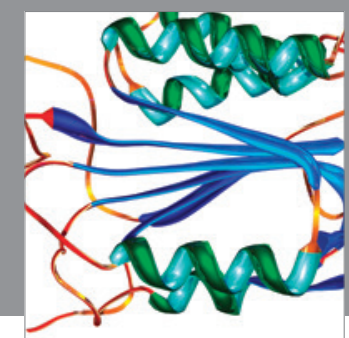

Disease Markers
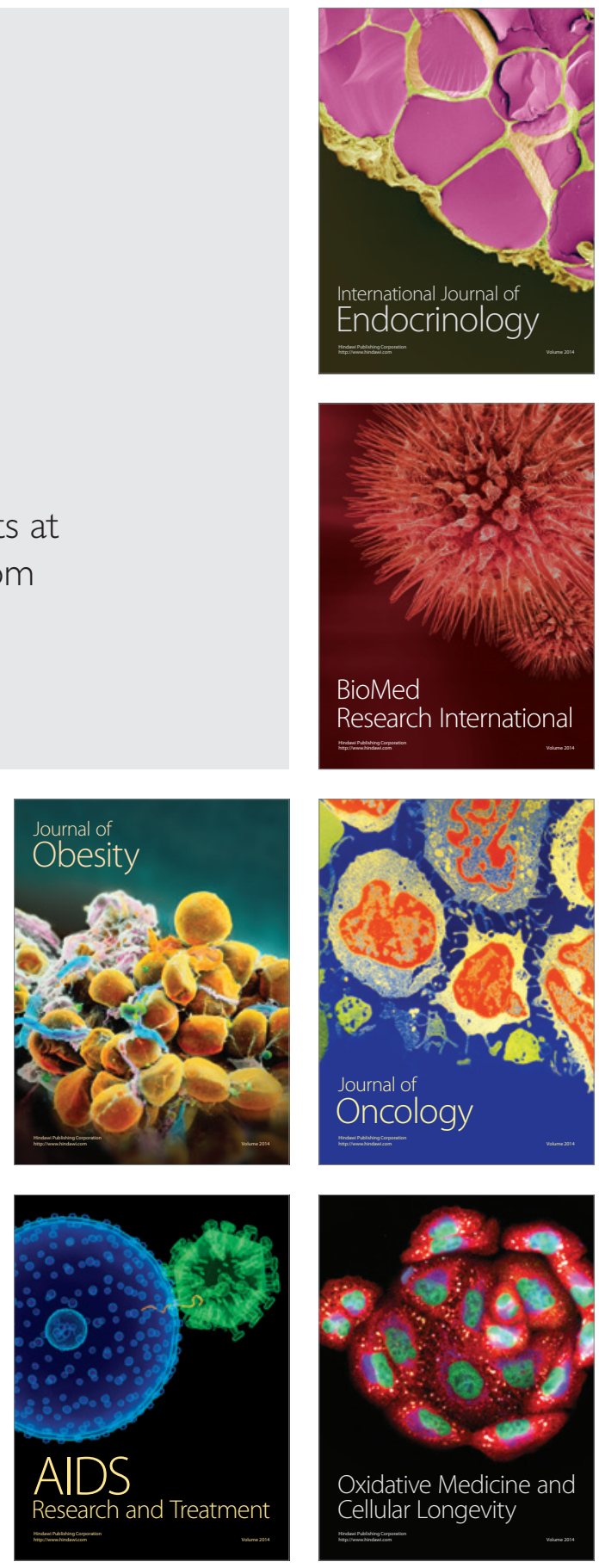